\title{
E-Ticaret İşlem Hacmi ve Tüketici Güven Endeksi Arasında Uzun Dönem İlişki Araştırması: Eşbütünleşme Analizi
}

\section{Aylin Kerime BİBERC $\dot{I}^{1}$}

\author{
Nazmi Y. YAĞANOĞLU $\mathbf{U}^{2}$
}

\section{Özet}

E-Ticaret, teknolojinin gelişmesi ile birlikte hayatımızda önemli bir yer edinmiş bulunmaktadır. Teknolojik gelişmelere oldukça bağlı olmasının yanı sıra tüketicilerin güveni ile de yakından ilgili olduğu aşikardır. Bu çalışmada E-Ticaret işlem hacmi ve tüketici güven endeksi arasındaki ilişki eşbütünleşme analizi yöntemlerinden olan ARDL yaklaşımı ve Durbin Watson yaklaşımı ile araştırılmıştır. Araştırmanın sonucunda sözü edilen iki değişken arasında uzun dönemli ilişki olmadı̆̆ı saptanmıştır.

Anahtar Kelimeler: E-Ticaret, tüketici güven indeksi, eşbütünleşme, ARDL

JEL Kodları: C01, D12, L81

\section{Analysis Of Long Term Relationship Between E-Commerce and Consumer Confidence Index: Cointegration Analysis}

\section{Abstract}

Due to continuous technological development of the internet, E-Commerce has become an important part of our lives. Among other things, it is logical to assume a close relatioship between the use of E-Commerce and consumer confidence. In this paper, we look for evidence of cointegration between volume of E-Commerce activities and the Consumer Confidence Index using ARDL and Durbin Watson approaches. We fail to detect any longterm relationship between the two variables.

Keywords: E-Commerce, consumer confidence index, cointegration, ARDL.

JEL Codes: C01, D12, L81

\footnotetext{
${ }^{1}$ Yüksek Lisans Öğrencisi, Çanakkale Onsekiz Mart Üniversitesi Sosyal Bilimler Enstitüsü, iktisat Politikası ABD, aylinbiberci@hotmail.com

${ }^{2}$ Dr.Öğr.Üyesi, Çanakkale Onsekiz Mart Üniversitesi Biga iiBß, Ekonometri Bölümü, nazmiyagan@comu.edu.tr
} 


\section{GİRIş}

Ülkemizde ve dünyada internet hızla büyüyen ve gelişen bir teknoloji ağıdır. İnternet ilk başlarda bilim adamlarının daha verimli ve hızlı bilgi üretmeleri, bilgi alışverişi yapıp bilgiyi paylaşmaları için ortaya çıkmıştır. İnternetin ortaya çıkışı ve kullanımı Dünya üzerinde ilk kez 1965 yılında Amerika'da gerçekleşmiştir.

Türkiye'de internet ile ilgili ilk çalışmalar 1980'li yıllarda başlamış; 1987'de Ege Üniversitesi öncülüğünde, Türkiye Üniversite ve Araştırma Kurumları Ağı (TÜKAVA) adıyla akademik ağ kurulmuştu. İlk akademik olmayan ve birçok kişi ve kurumu internet bağlantısına kavuşturmuş internet ağı projesi 1991'de ODTÜ ve TÜBİTAK tarafından başlatılmıştır.

ODTÜ yönlendiricileri ve 64 Kbps kapasiteli kiralık hat kullanılarak ilk internet bağlantısı 12 Nisan 1993'te gerçekleştirildi. İlk Türkçe içerikli web sitelerini ODTÜ ve Bilkent Üniversiteleri kurdu. Bunu daha sonrasında Mynet ve Ekşisözlük takip etti.

Türkiye'de E-Ticaretin başlaması, gelişimi ve yaygınlaşmasını da büyük ölçüde internet kullanımının yaygınlaşması olgusuna bağlayabiliriz. 1997 yılında Bilim ve Teknoloji Yüksek Kurulu, elektronik ticaret ağının yaratılması amacı ile toplandı ve bu şekilde elektronik ticaretin yolu açılmış oldu.

Elektronik ticaret; her türlü mal ve/veya hizmetin internet teknolojisi sayesinde elektronik ödeme sistemleri kullanılarak gerçekleştirilen satış işlemlerinin tümünü ifade eder.Geleneksel alışveriş yöntemlerine göre bazı avantajları ve farklılıkları vardır.

$-7 / 24$ alışveriş yapılabiliyor olması,

-İşletmenin çalışan maliyetlerine ve mağaza kira maliyetlerine katlanmıyor olması,

-Maliyetlerin fiyatlara da yansiması,

-Tüketici için daha çok ürün çeşidi bulunması gibi avantajları mevcuttur. Aşağıda ayrıntıları ile bahsedilecektir.

Ülkemizde ilk kurulan elektronik ticaret siteleri günümüzde de hala popüler olan Amazon ve E-Bay elektronik ticaret platformlarıdır. 1995 yılında kurulan bu elektronik ticaret sitelerinden Amazon.com'un kitap satışı ile insanoğlu ilk direk satış ile tanışmıştır. Türkiye'de 
elektronik ticaret başlangıcının, internet ile tanışma tarihinden kısa bir süre sonra olduğu söylenebilir.

GSYİH (Gayri Safi Yurtiçi Hasıla); bir ülke sınırları içerisinde belli bir zaman içinde üretilen tüm nihai mal ve hizmetlerin para birimi cinsinden değerini ifade eder. Bir ülkenin gayri safi yurtiçi hasılası o ülkenin nüfusuna bölündüğü zaman, kişi başına düşen GSYİH elde edilir.

GSYİH tüketicilerin satın alma gücünün belirleyicisidir. Gelir ve tüketim arasındaki ilişkiyi ortaya koyan Keynes; kişinin harcanabilir gelirinin tüketimin bir fonksiyonu olduğunu ve harcanabilir gelir ve tüketim arasında pozitif yönde bir ilişki olduğunu öne sürmüştür. Bu teoriye göre; kişinin harcanabilir geliri arttıkça tüketimi artar, kişinin geliri azaldıkça tüketimi de azalır. Böylece kişinin tüketimi arttıkça ticaretin de artacağı söylenebilir. Bu yüzden kişi başına Gsyih modele bağımsız değişken olarak eklenecektir.

\subsection{E-Ticaret Avantajları}

-Bir ürünün çok kısa bir sürede fiyatını, özelliklerini, nerede satıldığg hakkındaki bilgileri eşde etmemiz çok daha kısa bir süre almaktadır.

-Coğrafi engelleri ortadan kaldırır.

-Piyasalarda neredeyse tüketiciyi ve üreticiyi mükemmel bilgiye ulaştırır.

-Firmalar açısından bakıldığında dha hızlı bir şekilde, daha çok müşteriye erişim imkanı yakaladılar.

-İnternet sayesinde firmalar, en ucuz hammaddeye, ürün veya hizmete ulaşabilir.

-Küresel, daha geniş bir pazar mevcuttur.

-Üreticiler için farklı rakipler ve çok çeşitli tüketici grupları vardır.

-Küresel işbirliği ile yeni ürünler yeni fikirler ortaya çıkmaktadır.

- E-Ticaret ile birlikte satıcılar; farklılaştırılmış ürün rekabetinden, malların fiyat rekabetine geçmiştir.

İnternetin ekonomi açısından faydası; fiyatları daha şeffaf hale getirmesidir. Aradığımız ürünün fiyatını kontrol etmek, kıyaslamak internet ile çok mümkündür. Hatta 
fiyatları karşılaştırmak için programlar mevcuttur. Fiyat şeffaflaşması da bir anlamda komisyoncuların bu sistemin dışında kalmasını sağlıyor. Üretici ve tüketici çok daha hızlı bir şekilde buluşabilmektedir. Dolayısıyla üretici ve tüketici için çok geniş firsat ağları ortaya çıkmaktadır. 2011 'de internetin Türkiye ekonomisine yaklaşık 22 milyar TL yani GSYİH'nın yaklaşık \%1.7'si kadar katkısı olmuştur.

İnternetin tüketiciye vermiş olduğu önemli güçlerden biri de; tüketiciye en düşük fiyatı en iyi kaliteyi,en açık garanti koşulları sağlayan ürünleri önlerine sunuyor olmasıdır. Dolayısıyla ulaşımın ekonomik maliyeti ve bundan doğan zaman kaybı ortadan kaybolur. Bazen kargo ücretinin bile alınmadığı dönemler olduğunda daha düşük fiyat ile birçok ürünü elde etmek mümkündür. Hemen hemen herşey hakkında maliyetsiz bir bilgi söz konusudur. İnternet bedava bilgi sağlayarak piyasaları daha verimli hale getirir. Bundan dolayı internet kullanım oranı modele bağımsız değişken olarak eklenecektir.

\subsection{1.İnternet üzerinden yapılabilen işler;}

-İnternet üzerinden mal ve/veya hizmet satmak,

-Kişinin web sayfasında ücretli reklam alması,

-Bedava bilgi hizmeti ile birlikte sabit ücretli hizmet de sunmak vb.

\subsection{E-Ticaret Ödeme Sistemleri}

E-Ticarette alım-satım işlemi ve ödeme bilgisi akışı ilgili taraflar arasında sanal bir ortamda gerçekleşir. Ancak ödeme süreci gerçek alışveriş işlemleri ile aynı yolu izler. Gerçek ortamda müşteri kredi kartını satıcı da POS cihazını kullanır. Sanal ortamda müşteri kart numarasını, sanal satış sitesi de kartı kabul edebilmek için sanal POS yazılımı kullanır.

E-Ticarette bankalara gereksinim duyulur. Çünkü; güvenilir bir üçüncü tarafa ihtiyaç vardır. Yasal finansal işlemler için VISA ve Master Card ağlarını kullanan bir finansal kuruma ihtiyaç vardır.

\subsection{1.Ödemede Güvenlik}

-SSL Sistemi (Secure Sockets Layers): SSL internet ortamında en çok kullanılan güvenlik şifreleme yazılımıdır ve bütün yaygın web tarayıcıları ve sunucuları tarafından kabul edilmiş bir protokoldur. 
-SET Sistemi (Secure Electronic Transaction): Banka kartları ve ödemelerle ilgili bilgilerin güvenliğini sağlamak amacıyla VISA, Master Card, Netscape, GTE, IBM, SASC, Terisa Systems ve Verisign'in katılımı ile oluşan bir konsorsiyum tarafından gerçekleştirilmiştir.

SET sisteminin dört bileşeni vardır;

-Sanal Cüzdan: Müşterinin bilgisayarına kurulur. Bir güvenlik yazılımıdır. Müşterinin kimliğinin belirlenmesini sağlar.

-Sanal POS: Sanal ödeme yazılımıdır. Güvenli kart kabulünü ve satıcının kimliğinin belirlenmesini sağlar.

-Ödeme Geçidi: Bankanın finansal hizmetlerine erişim sağlar. İşlemler için güvenlik ve kimlik belirleme işi yapar.

-Sertifika Sağlayıcısı: Tarafların kullanmış olduğu tüm güvenlik anahtarlarının doğruluğunun ve sahibince kullanıldı̆̆ının garantisini verir.

\subsubsection{Mobil Ödeme Sistemi}

Alıcılar cep telefonu ile ödeme, satıcı da tahsilat yapar. Tutar fatura hatta faturaya, ön ödemeli hatta ise ön ödemeli hesaplardan düşülür. Banka müşterisi olmayan ya da kredi kartı sahibi olmayan kişiler veya internet ortamında kredi kartını güvenlik korkusu sebebiyle paylaşmak istemeyen kitle için önemli bir online ödeme aracıdır.

E-Ticaret ile ilgili yapılmış bazı çalışmalar aşağıdaki gibidir;

\section{LİTERATÜR}

Ülkemizde E-Ticaret hacmini etkileyen faktörlere ilişkin ekonometrik bir çalışma yapan Kayahan ve Hepaktan bağımsız değişken olarak 2005- 2015 yıllık verileri ile GSYİH, enflasyon oranı, penetrasyon oranı, kredi ve banka kullanıcı sayısı ve tüketici güven endeksi kullanılmıştır. Yöntem olarak ilk önce değişkenlere birim kök testi uygulayıp, daha sonra VAR analizi kullanmış ve varyans ayrıştırması, etki-tepki analizleri yapmıştır. Ayrıca eşbütünleşme testi de yapmıştır. Analizlerinin sonucunda kredi ve banka kullanıcı sayısı, GSYİH, tüketici güven endeksi ve internet bağlantı sayısı gibi faktörlerde meydana gelen bir artışın E-Ticareti olumlu etkilediği ortaya konulmuştur. (Kayahan ve Hepaktan, 2016) 
E-Ticareti etkileyen faktörleri panel veri analizi aracılığıyla saptamış ve bir tez çalışması ortaya koyan Baydar, 2003-2008 y1lı verileri ve 15 ülkenin; istihdam, enflasyon, eğitim, telekomünikasyon yatırımları, kişi başına GSYİH, internet kullanıcıları, geniş bant internet olan hanelerin verilerini kullanmıştır. Çalışmanın sonucunda; literatürde de olduğu gibi internet en anlamlı değişken çıkmıştır. Enflasyon ve kişi başına GSYİH da E-Ticareti etkileyen faktörlerdendir. Bu yüzden de çalışmamızda enflasyon değişkeni bağımsız değişken olarak kullanılacaktır. (Baydar, 2010)

Kişisel E-Ticaret uygulamalarının kategorik veri analizi yöntemleri ile değerlendirilmesi adlı çalışmasında Mann Whitney U testi ve Cochran-Mantel-Haenszel testi kullanan Arıcıgil ve Kuzu bulgularında E-Ticarete olan ilginin artması eğitim seviyesiyle ilişkilidir. Kişilerin eğitim seviyesi arttıkça bilişim teknolojileri kullanım oranı yükselir. Halkın internet konusunda bilinçlenmesi, E-Ticaretin büyüme hızını ve işlem hacmini artıracaktır, demiştir. (Arıcıgil ve Kuzu, 2013)

Türen, Gökmen ve Tokmak (2011), çalışmalarında E-Ticaret işlem hacmini, etkilediğini değerlendirdikleri İnternet kullanıcı sayısı, kişi başı GSYH, enflasyon, E-Ticareti destekleyen yasal mevzuat değişikliği, ekonomik kriz gibi faktörler ile çalışan Türen, Gökmen ve Tokmak söz konusu faktörlerin bağımsız değişken olarak tanımlandığı çoklu doğrusal regresyon modeli oluşturulmuş, E-Ticaret işlem hacmi üstündeki etkileri açıklamaya çalışılmışlar, elde edilen bulguları yorumlamışlardır. (Türen, Gökmen ve Tokmak, 2011)

Başka bir çalışmada ise; satıcıların, güven sistemini müşteri memnuniyetine ve sağladığı faydaya göre oluşturmaları gerektiğini savunmuştur. Çünkü, B2C E-Ticaret satışları müşterinin duyduğu güvene göre artış göstermektedir. Delone ve Maclean modeli ile çalış1lan araştırmada E-Ticaret ile ulaşılabilen ürün sayısının fazlalığı dikkate alınırsa genel başarısı yeterli değildir. Araştırmada yapılan analize göre E-Ticaretin başarısını; müşteri memnuniyeti, güven ve verilen hizmetin kalitesi belirlemektedir. (Brown ve Jayakody, 2008)

Bir araştırmaya göre, elektronik ticaret; gelişmekte olan ülkelerde makro ve mikro ekonomik birimler açısından kaynakların daha etkin kullanımını sağlayan firsatlar yaratmaktadır. Gelişmiş ülkelerde E-Ticarete ilişkin altyapı yatırımlarına önem verilmesi, yasal düzenlemelerin gerçekleştirilmesi; gelişmiş ülkelere E-Ticaretin fırsatları bakımından avantaj sağlamaktadır. Gelişmekte olan ülkelerin bu fırsatları değerlendirebilmesi için bu alanda yatırımları teşvik etmesi, yasal ve kurumsal engelleri düzenlemesi gerekmektedir. (Yumuşak, 2001) 


\section{ARAŞTIRMA YÖNTEMİ ve VERİ SETİ}

Çalışmada veri olarak kullanılan E-Ticaret işlem hacmi(LOGTİC-logaritmik düzeyde bir değişken) ve tüketici güven endeksi (TGE) değişkenleri sırasıyla Eurostat ve TÜİK'ten alınmıştır. Veri setlerinin kapsadığı dönemler aylık olup tarih aralığı ise 2014M012019M03'tür. E-Ticaret işlem hacmi değişkeni için yüzde ifade etmesi için logaritmas1 alınmış veriler ile çalışılmıştır. E-Ticaret işlem hacmi ve tüketici güven endeksi arasında uzun dönemli bir ilişski olup olmadığının test edilmesi için eşbütünleşme analizi yapılmıştır. Eşbütünleşme analizi yöntemlerinden ARDL yaklaşımı ile çalışılmıştır.

Eşbütünleşme analizi ele alınan ekonomik değişkenler arasında uzun dönemli bir ilişkinin varığını sınandığı istatistiksel bir analizdir. Eşbütünleşme iki veya daha fazla değişkenin uzun dönemli beraber hareketlerinin ilişkisini açığa çıkarır. Eğer değişkenler arasında uzun dönemli ilişkinin varlığından söz edilemiyorsa tahmin edilen regresyon sahte regresyon olmak durumundadir.

Sahte regresyon sorunu, tahmin edilen modellerin iyi sonuçlar verdiği yanılgısını ortaya çıkartabilir. Yani modelin aıklayıcı gücünü temsil eden R-kare oldukça yüksek, katsayılar istatistiki açıdan anlamlı çıkabilirler. Ancak bunun nedeni bu değişkenlerin birbirleriyle gerçekten ilişkili olmaları değil, durağan-dışı olan bu değişkenlerin tesadüfi olarak aynı yönde hareket etmeleri olabilir.

Sahte regresyona engel olabilmek için iki yol izlenebilir. İlki bilinen fark alma işlemidir. Durağan olmayan değişkenleri durağanlaştırmak için fark alınır. Ama durağanlaştırmak için farkı alınan bu değişkenler uzun dönem ilişkisini ortadan kaldırır. $\mathrm{Bu}$ yüzden uzun dönem ilişkisi için eşbütünleşme analizine başvurmak yerinde bir adım olacaktır.

Eşbütünleşme analizinin birçok yöntemi vardır. Bunlardan bir tanesi olan EngelGranger yaklaşımı ilk olarak 1981 yılında Granger tarafından öne sürülmüş ve daha sonra Engle-Granger 1987 yılında bir araştırmasında kullanıp, daha da geliştirmişlerdir. EngelGranger yöntemi ile yapılan eşbütünleşme analizi spesifikasyon hataları doğurabilir. Bunun nedeni temel modele gecikmelerin eklenmemesidir.

Bunun yerine gecikmeli değerleri de eklenen temel model yazılırsa, otoregresif dağıtılmış gecikme modeli elde edilir.

$$
Y t=\alpha+\Sigma \alpha j * Y t-j+\Sigma \beta i * X t-j+u t
$$


Burada ilk işimiz k'nın (gecikmelerin) ne olacağı hususudur. Gecikmeler LM, AIC, SIC gibi bilgi kriterleri sayesinde belirlenecektir.

ARDL analizinin yapılabilmesi için değişkenlerin birinci mertebeden I(1) tümleşik olmaları gerekir. Bunun için değişkenlere ADF (Augmented Dickey Fuller) birim kök testi yaptırılacaktır. Bunun da öncesinde ardışık süreç yaklaşımı ile değişkenlere ait uygun modelin hangisinin olduğu saptanmıştır.

Ardışık süreç yaklaşımı kullanılarak hem E-Ticaret hem de tüketici güven endeksi serileri için kesmesiz trendsiz modelin uygun olduğu sonucuna ulaş1lır.

Tablo 1

\begin{tabular}{|c|c|c|c|c|}
\hline \multirow{2}{*}{ ADF(p) } & \multicolumn{2}{|c|}{ DÜZEY } & \multicolumn{2}{c|}{ BİRINCİ FARK } \\
\cline { 2 - 5 } & LOGTİC & TGE & LOGTİC & TGE \\
\cline { 2 - 5 } & $2,847(1)$ & - & - & - \\
& $0,848(9)$ & $13,968 *(0)$ & $7,338^{*}(0)$ \\
\hline
\end{tabular}

Not: * \%1 düzeyinde anlaml

** $\% 2$ düzeyinde anlaml

*** \%3 düzeyinde anlamlı

LOGTİC ve TGE değişkenleri için eşbütünleşme analizi, ARDL yaklaşımı kullanılarak yapılacaktır. Bunun için değişkenlerin her ikisinin de birinci mertebeden entegre (aynı mertebeden tümleşik) olmaları gerekmektedir. Yukarıdaki Tablo 1 incelendiğinde;

LOGTİC serisinin düzeyde durağan olmayıp, birim kök içerdiği saptanmış olup, birinci farkı alındığında serinin durağan hale geldiği görülmektedir. Yani LOGTİC serisi I(1) birinci dereceden entegre bir seridir.

Aynı şekilde TGE serisi için de düzeyde yapılan birim kök testi neticesinde birim kökün varlığına rastlanılmış olup, birinci farkı alındığında serinin durağanlaştığı yani TGE serisinin de birinci dereceden entegre bir seri I(1) olduğu kanısına varılmıştır.

Bu noktadan sonra artık eşbütünleşme analizine adım atılabilir. Öncelikle spesifikasyon hatası ile karşılaşmamak adına temel modele eklenecek gecikmelerin belirlenmesi gerektiğinden, gecikmeler belirlenmiştir. Tablo 2'de sonuçları yer almaktadır. 
Tablo 2

\begin{tabular}{|c|c|c|c|}
\hline & \multicolumn{3}{|c|}{ Gecikme Sayısı } \\
\hline Kriter & $\underline{\mathbf{0}}$ & $\underline{\mathbf{1}}$ & $\underline{\mathbf{2}}$ \\
\hline $\boldsymbol{A I C}$ & 5,35 & 5,38 & 5,34 \\
\hline SIC & 5,45 & 5,51 & 5,51 \\
\hline $\boldsymbol{L M}$ & 4,23 & 3,21 & 3,12 \\
Prob. & 0,1206 & 0,0942 & 0,0925 \\
\hline
\end{tabular}

Gecikmelerin sayısını belirlemek için paket programa otomatik yaptırmak yerine elle deneyerek hata terimindeki serisel korelasyonun ortadan kalkana kadar gecikme eklenmesi ile bulunmuştur. Yukaridaki tablolardan ilki TGE değişkeni için (LM Prob. $=0,1206$ ) yani p=0 gecikme için hata terimi serisel olarak korelasyonlu olmadığından TGE değişkeni için gecikme sayısı $\mathrm{p}=0$ uygun görülmüştür.

Tablo 3

\begin{tabular}{|c|c|c|c|}
\hline & \multicolumn{3}{|c|}{ Gecikme Sayısı } \\
\hline Kriter & $\underline{\mathbf{0}}$ & $\underline{\mathbf{1}}$ & $\underline{\mathbf{2}}$ \\
\hline $\boldsymbol{A I C}$ & $-3,75$ & $-4,03$ & $-4,01$ \\
\hline SIC & $-3,64$ & $-3,89$ & $-3,84$ \\
\hline $\boldsymbol{L M}$ & 17,50 & 7,65 & 2,93 \\
Prob. & 0,0002 & 0,0218 & 0,2309 \\
\hline
\end{tabular}

Tablo 3'te ise; LOGTİC değişkeni için uygun gecikme aynı yöntem ile belirlenmiştir ve $(p=3)$ gecikme için hata terimindeki serisel korelasyon ortadan kalktığı için (LM Prob.= 0,2308) LOGTİC uygun gecikmesi ise $\mathrm{p}=3$ seçilmiştir.

Değişkenlerin uygun gecikmeleri ile birlikte model tahmin edilmiştir ve sonuçları Tablo 4'teki gibidir. 
Tablo 4

\begin{tabular}{|l|c|c|c|c|}
\hline $\begin{array}{l}\text { Bă̆ımlı Dĕğişken: } \\
\text { LOGTIC }\end{array}$ & Parametre & $\begin{array}{c}\text { Standart } \\
\text { Hata }\end{array}$ & T-istatistiği & Prob. \\
\hline TGEt & 0,000499 & 0,000719 & $-0,694$ & 0,4902 \\
\hline LOGTICt-1 & 0,266 & 0,13 & 2,102 & 0,0400 \\
\hline LOGTICt-2 & 0,481 & 0,11 & 4,160 & 0,0001 \\
\hline LOGTICt-3 & 0,259 & 0,12 & 2,169 & 0,0344 \\
\hline
\end{tabular}

R-squared: 0,953

SSR: 0,056

Adj. R-squared: 0,951

LR: 124,2300

Durbin Watson (DW): 2,153

LM (2) F-stat: 3,76 - Prob: 0,1523

AIC: $-4,00$

F-stat: 1,80- Prob: 0,1739

SIC: $-3,86$

-Bu tablodan hareketle uzun dönem katsayıları hesaplanmıştır.

$\mathrm{Y}^{*}=\alpha^{*}+\beta^{*} \mathrm{TGE}$

$\mathrm{B}^{*}=\Sigma \beta \mathrm{i} / 1-\Sigma \alpha \mathrm{i}=-0,000499 / 1-(0,266+0,481+0,259)=0,0832$

-Yani buradan uzun dönem ilişkisini belirten eștümleştirme modelimiz;

LOGTICt $=0,0832($ TGEt $)$

-Kalıntılar ise;

$\hat{U} \mathrm{t}=$ LOGTİCt $-0,0832($ TGEt $)$

-Kalıntı serisinde durağanlık analizi için birim kök uygulanmıştır. Aşağıda sonuçları verilmektedir.

$$
\Delta \text { ût }=0,022(\text { ût })+0,137(\text { ût-1) }-0,321(\text { ût-2) }-0,105(\text { ût-3) }-0,285(\text { ût-4) }+0,067(\text { ût-5) - }
$$

$0,207($ ût-6) $+0,052($ ût-7) $-0,369($ ût-8) $+0,338($ ût-9) 
Tablo 5

\begin{tabular}{|l|l|lc|}
\hline \multirow{4}{*}{$\mathrm{ADF}(\mathrm{p})$} & \multicolumn{2}{|l|}{ Kalıntılar $(\hat{\mathrm{u}})$} & \multicolumn{2}{|c|}{$\mathrm{m}=2$ için kritik değerler } \\
\cline { 2 - 4 } & \multirow{2}{*}{$0,9386(9)$} & $\% 1$ & $-3,95$ \\
\cline { 3 - 4 } & & $\% 5$ & $-3,37$ \\
\cline { 3 - 4 } & & $\% 10$ & $-3,07$ \\
\hline
\end{tabular}

Not: Kalıntı serisine uygulanan birim kök testi kesmesiz trendsiz modele göre yapılmıştır.

H0: $\delta=0 \quad \mathrm{t} \delta>\mathrm{c}(\mathrm{p})$ ise ût durağan-dışıdır, eşbütünleşme yoktur.

$\mathrm{H} 1: \delta<0 \quad \mathrm{t} \delta \leq \mathrm{c}(\mathrm{p})$ ise ût durağandır, eşbütünleşme vardır.

Hesaplanmış olan 0,9386 t $\delta$ değeri, tüm anlamlılık düzeylerindeki kritik değerlerden daha büyüktür. Yani eşbütünleşme olmadığını belirten boş hipotez ret edilememektedir. $\mathrm{Bu}$ durum ût'nin durağan olmadığını, LOGTİC ve TGE değişkenlerinin eşbütünleşik olmadığını anlatır.

\section{DURBIN WATSON YAKLAŞIMI}

Eşbütünleşme analizi için kullanılabilecek yöntemlerden bir diğeri olan DurbinWatson yaklaşımıdır. Bu yaklaşım 1983 yılında Sargan ve Bhargava tarafından ortaya atılmıştır.

Drurbin-Watson sınaması için kullanılacak olan hipotezler aşağıdaki gibidir;

H0: d=0 (Kalıntılar durağan-dışı, eşbütünleşme yok)

H1: d >0 (Kalıntılar durağan, eşbütünleşme var)

-Kesmeyi ve trendi modele ekleyerek model tahmin edildiğinde aşağıdaki sonuçları vermiştir;

LOGTİCt $=7,27+0,0075 \mathrm{t}-0,0020 \mathrm{TGEt} \quad$ DW:1,486

t-ist. $\quad(101,49) \quad(27,23) \quad(-2,054)$

Tahmin sonuçlarının verdiği DW:1,486 çıkmıştır. Kullanılacak kritik değerler sırasıyla $\% 1, \% 5$ ve $\% 10$ anlamlılık düzeylerinde $0,511,0,386$ ve 0,322 değerlerinden büyük olduğundan boş hipoez retedilmektedir. Yani LOGTİC ve TGE arasında uzun dönem ilişkisi 
vardır. Ancak bu sonucun doğruluğunda kesme ve trendin varlığı sebep gösterilebilir. Çünkü en başta yapılan ardışık süreç yaklaşımında hem LOGTIC hem de TGE değişskenleri için uygun model kesmesiz trendsiz bulunmuştu, kesme ve/veya trend teriminin olmadiğ hipotez retedilememişti.

-Bu yüzden bu düşünceden hareketle trend dişlanarak kesmeli trendsiz model ve her ikisi de dışlanarak kesmesiz ve trendsiz model ile DW yaklaşımı yeniden incelendiğinde aşağıdaki sonuçlar bulunmuştur;

$$
\text { LOGTİCt }=8,26-0,013 \mathrm{TGE}+\text { ut } \quad \text { DW: } 0,26
$$

t-ist. $\quad(36,99) \quad(-4,042)$

-Kesmeli trendsiz model için DW=0,26 $<0,511$

$$
\begin{aligned}
& 0,386 \\
& 0,322
\end{aligned}
$$

olduğundan LOGTİC ve TGE arasında eşbütünleşme yoktur.

$$
\text { LOGTICt }=0,107 \text { TGEt }+ \text { ut } \quad \text { DW=0,31 }
$$

t-ist. $\quad(92,40)$

-Kesme ve trend içermeyen model için $\mathrm{DW}=0,31<0,511$

$$
0,386
$$

0,322

olduğundan LOGTIC ve TGE arasında eşbütünleşme yoktur.

\section{SONUÇ}

2014M01-2019M03 aylık verilerini kapsayan çalışmamızda E-Ticaret işlem hacmi ve tüketici güven endeksi arasındaki ilişki eşbütünleşme analizi yardımıyla incelenmiştir. İki veya daha fazla değişken arasında uzun dönemli bir ilişkinin varlığını sınayan bu analize göre öncelikle değişkenlerin her birinin birinci mertebeden entegre olma şartı yerine getirilmiş, değişkenlere uygulanan birim kök testi sonuçları her iki değişkenin de birinci farkında durağan hale geldiği görülmüştür ve böylelikle eşbütünleşme analizine başlanmıştır. 
Eşbütünleşme analizi yöntemlerinden olan ARDL yaklaşımı ve Durbin Watson yaklaşımı kullanılmıştır. ARDL yaklaşımı temel modele gecikmelerin eklenmesi ile spesifikasyon hatalarını elimine ettiğinden, Durbin Watson yaklaşımı ise; pratik ve yaklaşık bir sonuca ulaşmamızı sağladığından dolayı çalışmada tercih edilen yöntemlerden olmuşlardır.

Her iki eşbütünleşme analizi yönteminin sonucunda da aynı sonuca ulaşılmıştır. ETicaret işlem hacmi ve tüketici güven endeksi arasında uzun dönem ilişki yoktur, eştümleşik değillerdir. Bu durumda aralarında uzun dönem ilişki olmadığından bu değişkenlerle tahmin edilecek regresyon modeli sahte olacak ve tesadüfi olarak iyi sonuçlar verecektir.

\section{KAYNAKÇA}

Kayahan, L. (2016), “Türkiye’de Elektronik Ticaret Hacmini Etkileyen Faktörlere İlişkin Var Analizi”, İktisadi ve İdari Bilimler Fakültesi Dergisi.

Baydar, V. (2010), "E-Ticaret Kavramı ve E-Ticareti Etkileyen Faktörlerin Panel VeriAnalizi”, Süleyman DEMIREL Üniversitesi Doctoral dissertation, Sosyal Bilimler.

Çilan, Ç. A., \& Kuzu S., (2013), "Kişisel E-Ticaret Uygulamalarının Kategorik Veri Analizi Yöntemleri ile Değerlendirilmesi”,. Alphanumeric Journal, 1(1), 27-32.

Türen, U., Gökmen, Y., \& Tokmak, İ. (2011), “Türkiye'de E-Ticaret İşlem Hacmini Etkileyen Faktörler Üzerine Bir Araştırma: Bir Model Önerisi”, Savunma Bilimleri Dergisi, $10(1), 49-71$.

Brown, I., \& Jayakody, R. (2008), “ B2C E-commerce Success: A test and validation of a revised conceptual model", The Electronic Journal Information Systems Evaluation, $11(3), 167-184$.

Yumuşak, İ. G. (2001), "Elektronik Ticaretin Gelişmekte Olan Ülkelere Etkileri ve Türkiye Üzerine Bir Değerlendirme”,. Çevrimiçi http://128.118, 178. 